\title{
Arquivos de glória e de repúdio: mudanças de paradigma e de valores no New Burlesque
}

\section{Archives of glory and repudiation: paradigm and value shifts in New Burlesque}

Gabriela Maffazzoni Chultz ${ }^{1}$

Suzane Weber Silva ${ }^{2}$ 


\section{Resumo}

Partindo da ideia de arquivos e de reenactman, propomos rever certos momentos da arte burlesca, analisando a dimensão do corpo (sobretudo dançante) na esfera da sensualidade, os distintos regimes de valor envolvidos, além do protagonismo da mulher. Lançamos a questão: como a centenária prática burlesca pode ser analisada sob o prisma de uma manifestação reencenada e reinventada por artistas? O recorte relaciona-se a observação da questão de gênero enquanto atitude de vanguarda, evidenciando o que se refere à ousadia da exibição de corpos de mulheres. Com o intuito de preservar certos arquivos, aproximamos 0 fenômeno evolutivo do burlesco a um panorama cultural da história da dança.

Palavras-chave: Dança; Burlesco; new-burlesque; valor; mulher

\section{Abstract}

Starting from the idea of archives and reenactman, we propose to review certain moments of burlesque art, analyzing the dimension of the body (dancing body) in the realm of sensuality, the different value regimes involved, and the role of women. We launch the question: how the burlesque centenary practice can be analyzed under the prism of a manifestation reencountered and reinvented by artists? The clipping is related to the observation of gender issue as a vanguard attitude, evidencing what refers to the daring of the exhibition of women's bodies. In order to preserve certain archives, we approximate the evolutionary phenomenon of burlesque to a cultural panorama of dance history.

Keywords: Dance; burlesque; new-burlesque; value; woman

E-ISSN: 2358.6958

\footnotetext{
Doutoranda em artes cênicas pelo Programa de Pós-Graduação em Artes Cênicas (UFRGS). Foco de pesquisa em dança/ mulheres/danças populares/mercado de trabalho.gabriela_chu@hotmail.com

2 Professora PhD Associada do Departamento de Teatro e professora do Programa de Pós-Graduação em Artes Cênicas da Universidade Federal do Rio Grande do Sul (PPGAC/UFRGS). ssuzaneweber@gmail.com
} 
As noções de reenaction, reanimating e reenactman na arte indicam não a simples repetição de eventos passados ou seu arquivamento como artefatos de museu (Franko, 2015, p.50), mas uma ideia de re-work, de refazer e de recriar. Não se trata de negar o passado, mas revisitá-lo, questioná-lo, estudá-lo, desdobrá-lo e recriá-lo através da memória. "A questão da autenticidade foi deslocada pela questão do arquivo"3 (Franko, 2015, p. 52).

Nesse artigo, estaremos ${ }^{4}$ guiadas pela ideia de arquivo para notá-la na prática corporal e artística do burlesco. O corpo como lugar de atualização dessa arte e de reinterpretação de valores (morais, sociais, históricos). A noção de arquivo está presente na proposta cronológica do artigo enquanto recurso político, de permanência, desafiando e problematizando o risco da efemeridade dos atos performativos (Taylor, 2013). Ao mesmo tempo, tal noção se contrapõe à ausência de certas narrativas na história tradicional e hegemônica da arte, da dança (Dodds, 2011).

A palavra burlesco (italiano: burlesco, burla, farsa ${ }^{5}$ ), pode ser reconhecida hoje em certos contextos enquanto arte (envolvendo o cantar, o interpretar, o dançar), entretenimento e, ao mesmo tempo, enquanto discurso político de poder, sobretudo relacionado ao corpo da mulher. Corpo esse sujeito de uma expressão artística e de sugestão erótica, provocador em diferentes esferas, seja ela política, sensual, sexual, desejante e até na dimensão subjetiva do sujeito artista e do espectador. Conforme o significado apresentado pelo Dicionário de Teatro de Patrice Pavis (1999), o burlesco torna-se gênero literário em meados do século XVII na França, e é explicado pela sua forma literária cômica, pastiche, grotesca, para tratar de assuntos nobres e elevados. Chamo ainda a atenção para a visão de Pavis de reconhecer no burlesco um principio estético de composição, "que consiste em inverter os signos do universo representado..." (Pavis, 1999, p. 36).

Segundo Annie Suquet (2012), o burlesco enquanto gênero teatral está presente na modernidade, no momento da ascensão das grandes metrópoles em meados do século XIX para o início do século XX, período marcado pelo nascimento do show-business. O burlesco aparece como uma espécie de interlúdio cômico, com sugestão erótica difusa, concorrendo ou sendo acolhido pelo teatro de variedades ${ }^{6}$. Nessa virada do século, no burlesco as mulheres interpretavam papéis masculinos de modo cômico. Não interpretavam a figura realista de um homem em cena, mas comentários e gestos que apontavam o traje masculino, ou a performatividade masculina ${ }^{7}$, enquanto objeto de fetiche. Em cada um dos distintos momentos históricos em que se desenvolve, o burlesco promove concepções culturais e sociais diversos que se renovam, refletindo assim diferentes regimes de valor (Frow, 1995).

\footnotetext{
3 "The question of authenticity has been displaced by the question of the archive" (Tradução nossa).

4 Esse artigo faz parte de um estudo que está sendo desenvolvido em nível de doutorado e se intitula "A mulher na arte do burlesco: valores, incorporações e mercado de trabalho". Salientamos que, ao adentrar neste artigo, o leitor notará uma alternância entre o eu e o nós, consequência dos diálogos e desejos entre a artista-pesquisadora de doutorado Me. Gabriela Maffazzoni Chultz (quem escreve e conta experiências próprias) e de sua orientadora Dra. Suzane Weber da Silva.

5 Italien burlesco, de burla, farce (Larousse Dictionnaires de Français). (Tradução nossa).

6 Suquet (2012) destaca a hibridação dos gêneros da época tais como o extravaganza, music-hall, teatro de variedades, burlesco, ballet, etc.

Nesse artigo, ao falarmos de performatividade masculina, somos influenciadas pelo pensamento de Judith Butler (2003) no sentido de compreender que a performatividade de gênero se trata de gestos, de atos e de signos, dentro de um âmbito cultura e social, associados a posições binárias tais como macho e fêmea, masculino e feminino, pênis e vagina dentro de uma matriz de heteronormatividade.
} 
Em conexão com a ideia de reenactement de Franko (2015) que motiva conceitos de ação indicando o refazer algo, o refletir sobre, nos questionamos como a centenária prática burlesca pode ser analisada sob o prisma de uma manifestação reencenada e reinventada por artistas, especialmente artistas mulheres. Nessa reinvenção do burlesco acreditamos que é possível destacar novos contornos e representatividades dentro do campo artístico e do campo social, sugerindo possíveis valores ligados à autonomia artística, ao protagonismo das mulheres, e ao mercado de trabalho em arte e suas relações com a manutenção de poder na sociedade. É válido lembrar que o burlesco desde que emergiu esteve, de certo modo, à margem, buscando confundir, provocar e desestabilizar certas hierarquias da cena teatral. Dessa forma, e a partir desses pressupostos, reflexões que tangem o social se fazem presentes para discutir aspectos intrínsecos à prática artística em questão.

Para examinar o questionamento feito no parágrafo anterior - como a centenária prática burlesca pode ser analisada sob o prisma de uma manifestação reencenada e reinventada por artistas... - estaremos embasadas na investigação de autores do campo da dança ${ }^{8}$ tais como os norte-americanos Sherril Dodds (2011) ${ }^{9}$ e Mark Franko (2015) e as europeias Annie Suquet (2012) e Boulbès (2014). Além disso, o artigo se embasa em referências práticas e reflexivas especializadas em dança e teatro através de experiências pessoais da autora.

\section{Cronologia - archives de glória e repúdio}

Ao escolher momentos de uma cronologia do burlesco, Dodds (2011) mantém o foco em verificar as rearticulações de estruturas de valores em relação ao undress, ao desnudar, presente no strip-tease neo-burlesque. Para a autora, discursos são disparados ao se produzir um corpo strip-tease inscrito em um contexto político de produção. Discursos tais como o da autonomia e o das políticas de inclusão, discursos em torno de diferentes valores; não esquecendo os valores econômicos associados a essa prática, que disparam ainda outras considerações em direção às questões de gênero, de classe e de raça. A seguir, realizo uma apresentação cronológica do burlesco com foco no jogo de incorporações de distintos valores, flutuantes. Arquivos de glória e de repúdio. Para tanto, proponho uma linha cronológica inspirada em Dodds, interpondo outras referências que estão de acordo como uma análise cultural dessa trajetória, sugerindo assim possíveis inserções do burlesco na história cultural da dança.

Oscilando entre o sucesso e o fracasso, entre valorização e desvalorização, a prática burlesca ocupou historicamente uma posição de "low art" (baixa cultura ou cultura popular). No entanto, inspirada pela ideia de valores que jogam, que flutuam, apontamos para a possibilidade de mudança de paradigma nos cânones de legitimidade artística pensando em um contexto onde o capital cultural é elevado, tal como o meio acadêmico de pesquisa - uma vez que certas noções, presentes no universo do burlesco, passam por revisões: como o erótico, o humor, o entretenimento e as possíveis formas de ser político, sem esquecer o protagonismo da mulher na modernidade.

\footnotetext{
8 Optamos por valorizar autores da dança nesse debate visto que é nosso campo de pesquisa primeiro, e pelo fato de localizarmos expressivas referências desse campo tratando sobre burlesco enquanto plataforma de números individuais performados, dançados por mulheres.

9 Sheril Dodds dançarina e pesquisadora americana na Temple University (EUA).
} 
A perspectiva da história cultural nos últimos anos tem revisto certas manifestações da modernidade ${ }^{10}$ no que se refere à participação da mulher no universo da arte ao ingressar no mercado de trabalho. Reconsideram-se assim certas artistas que atuavam em meio alternativos tais como cabaret, teatro de variedades e music-hall. Analisando a perspectiva de gênero, essas práticas, que até algumas décadas atrás eram desvalorizadas, associadas a um reforço do patriarcado e julgadas sem valor artístico, de modo paradoxal, tem sido revisitada através de publicações tais como Boulbès (2014) e Suquet (2012), para citar estudos estrangeiros que operam diretamente no campo da dança; e através de autoras brasileiras como Neyde Veneziano $(1991,1996,2005,2010)$ que, ao abrir portas para a relevância do teatro de revista, de variedades e musical brasileiro, revela a importância das vedetes e de seus trabalhos cênicos e culturais, bem como de ruptura moral.

Adentrando na cronologia proposta, o termo - Burla aparece primeiro para designar um gênero literário italiano, uma tendência de satirizar narrativas e poesias no século XVI (Dodds, 2011). Burla, portanto, guarda todos os significados ligados ao intento de burlar, enganar, fazer graça, provocar o riso, sugerindo comicidade e/ou algo pejorativo. Em meados do século XIX, a palavra conectou-se ao gênero performativo, através do papel das travesties ${ }^{11}$ (na maioria dos casos homens em papeis femininos) e das pantomimes ${ }^{12}$, assumindo influência da Commedia dell 'Arte, italiana. Esse seria um estilo presente no Reino Unido, com base em contos de fadas ou lendas populares, tais como a Cinderela, para citar um dos mais famosos, apresentando números de comicidades e de teatro musical.

O burlesco só fora compreendido como plataforma de espetáculos femininos no final do século XIX e evidenciando-se no início do século XX, a ser notado através do nome de Lydia Thompson (1838-1908) (performer de Music Hall) e sua trupe Britsh Blodes em Nova Iorque. Em 1866, George Wood, proprietário de alguns teatros de Manhattan, convidou Thompson para se apresentar no seu teatro da Broadway de 1.302 lugares, proposta que veio a se concretizar somente em 1868, pois ela já havia se comprometido com apresentações no Prince of Wales Theatre, em Londres (Allen, 1991, p.3), outro centro chave para a cronologia burlesca.

A figura de Thompson causou rebuliço em sua época e veio atestar o início de uma forte inversão de valores ligados ao feminino e, sobretudo, relativos às ideologias da era vitoriana (1837-1901) e seu ideal de feminino: mulheres magras, pálidas, assexuadas, naturais e delicadas. Thompson exibia características contrastantes ao padrão: mulher voluptuosa, loira, maquiada, sexualizada, e que jogava entre parecer com aspectos masculinos da época, e, ao mesmo tempo, parecer feminina.

\footnotetext{
10 Estamos baseadas em aspectos da modernidade a partir do livro L'Eveil Des Modernites. Une Histoire Culturelle De La Danse (1870-1945), de Annie Suquet (2016). O contexto que nos referimos acompanha o período analisado pelo livro, o qual destaca a ascensão das cidades e a evolução de costumes, e aponta para novas formas de entretenimento que surgiram no Ocidente. Com essas mudanças, renovadas visões do corpo dançante aparecem, múltiplas e por vezes contraditórias. O burlesco e as danças ditas "exóticas" configuram-se nesse contexto ao desenharem inspirações libertadoras.

11 A figura de mulheres em cena era realizada muitas vezes por travesties, dada à impossibilidade de participação das mulheres em cena.

12 Para saber mais sugiro a consulta através do link: http://www.its-behind-you.com/download.html
} 
Também no ano de 1866 o público nova-iorquino descobre a grandiosa e a mais cara produção da cena americana da época: The Black Crook, espetáculo referente a um novo gênero que surgia, a Extravaganza ${ }^{13}$. Assim, no teatro Niblo's Garden, o espetáculo The Black Crook (1866) emergiu como o primeiro grande sucesso de divertimento comercial nos Estados Unidos, marcando a história do teatro musical norte-americano e fomentando o nascimento da indústria do show business e das grandes turnês.

Outra referência que se destaca, ainda no século XIX, surgiu na cidade de Manchester na Inglaterra, The Tiller Girls, em 1890 com destaque para o nome do britânico John Tiller (1854-1925) e seu "business de la jambe"14 - que teve alta repercussão e caracterizou-se por números compostos por muitas dançarinas de estatura e peso próximos, atitude enérgica, com grande precisão técnica de linhas e postura, além da ênfase na elevação de pernas. Ao final dos anos 1890, então, pode se dizer que o business de la jambe atingiu um importante e duradouro reconhecimento (Suquet, 2012).

Nos anos de 1920, agora com o espetáculo intitulado Le Girls no Theatrical Revue, que além de ser reconhecido pela sua carga erótica representada pela liberdade das pernas a mostra, também fora reconhecido pela sua técnica cênica e coreográfica incrível de uniformização dos movimentos, demarcou a presença de um mercado forte no entretenimento, protagonizado por mulheres, e que gerou uma série de controvérsias sobre a noção de nudez, entre outras reações ambivalentes. Le Girls foi visto também enquanto um modelo e produto da civilização industrial, por conta da imagem das pernas em série e em sincronia, como se correspondessem às próprias mãos das usinas (Suquet, 2012, 65), e "... elas também produzem a imagem positiva de uma nova forma de totalidade e harmonia coletiva que preencheria a falta física precisamente causada pelo estouro da experiência da vida moderna e da solidão nas grandes cidades" (Suquet, 2012, 65/66)15. O music-hall, seguindo a onda de sucesso dos espetáculos femininos, tanto na Europa como na América, descobriu a eficiência do método de entretenimento elaborado por John Tiller e a replicou, reforçando um fenômeno.

\section{O fenômeno da industrialização e do business das pernas}

O burlesco, junto a outras formas populares de entretenimento e arte, fez parte, portanto, de um complexo e transformador fenômeno artístico, social, cultural e econômico, sobretudo no hemisfério norte. O sucesso comercial de certos espetáculos do século XIX, como citamos acima, também esteve ligado ao período da revolução industrial e marca ou auge da modernidade. O desenvolvimento da malha ferroviária tornou-se decisivo para eclodir manifestações artísticas e outras atividades nas grandes cidades, centros nevrálgicos de expansão econô-

\footnotetext{
13 Gênero de espetáculo americano que misturava o melodrama de inspiração romântica entre fadas e efeitos especiais, danças clássicas e números acrobáticos. Ele surge no século XIX, e segundo o dicionário Laurrousse de la danse (2008) o termo aparece em 1957. O melhor exemplo de extravaganza é o espetáculo The Black Crook (1866).

14 Expressão que poderia ser traduzida como um mercado das pernas, referente ao trabalho técnico realizado com o lançamento das pernas ao alto, quase como 'esse trabalho foi reconhecido pelo alinhamento e precisão dos movimentos em coro e décadas depois foi absorvido pelo cinema de Hollywood.

15 “... elles produisent aussi l'image positive d'une nouvelle forme de totalité et d'harmonie collective qui viendrait combler le manque physique précisément provoqué par l'éclatement de l'expérience propre à la vie moderne et à la solitude dans les grandes villes". (Tradução nossa)
} 
mica e de mercado pelas ferrovias, não só as mercadorias circulavam de forma mais intensa, mas também os homens, as ideias, a arte, as informações (Suquet, 2012). A massa flutuante de pessoas trabalhando incentivou o surgimento de um novo mercado nas grandes cidades, o do entretenimento ligado às artes da cena, o show business. Multiplicaram-se assim o número de bares, teatros, cabarés e outras salas de espetáculos próximos aos eixos urbanos e comerciais para serem usufruídos no período após o trabalho.

Criou-se um novo mercado, cultural, conectado às demandas cotidianas de uma época. Nas casas e bares as apresentações poderiam ser assistidas em pé, e poderia se beber (álcool) e comer, hábitos e costumes populares permitidos e que se diferenciavam das regras de outros espaços culturais frequentados pela elite. $O$ vaudeville, por exemplo, era a verdadeira voz da cidade, atendendo as demandas populares. Como protagonista desse fenômeno, o corpo dançante feminino demonstrava forte carga erótica através da liberdade de exposição e de seus movimentos. Tais práticas (falando dos estilos burlesque, music hall, revue, vaudeville) impulsionaram mudanças de pensamento sobre práticas cotidianas de mulheres da classe média ${ }^{16}$.

\section{O exótico e o erótico}

Nos anos de 1890 as chamadas danças exóticas e eróticas tiveram grande repercussão. Assim, de forma exótica, foi vista a dança do ventre ${ }^{17}$ nos Estados Unidos, bem como o burlesco (Suquet, 2012, p.64), essa última, uma arte estabelecida dentro do American show business. No entanto, mesmo com sua forte propagação, o burlesco continuava a representar um caráter "low art", um entretenimento a ser apreciado em casas de divertimento para homens. Já ao popular vaudeville foram atribuídas características mais polidas, com maior controle do público, e ao burlesco faltavam esses valores da classe média, faltava certa moral (Dodds, 2011).

Nomes da dança moderna, tais como Loïe Fuller (1862-1928), Isadora Duncan (1877-1927) e Ruth Saint Denis (1879-1968), tentaram se distanciar do erótico e do divertimento de massa de modo a obter certa distinção em busca de uma maior identidade artística e reconhecimento (Suquet, 2012). Assim, as dançarinas consideradas 'exóticas'18 que envolviam sedução e transgressão erótica estiveram à luz de uma epistemologia visual reduzida a ideia de objeto de desejo masculino e mal vistas pelas dançarinas modernas (Boulbès, 2014). A nudez, no contexto da modernidade, era permitida e bem quista apenas se associada a valores do feminino ligados à natureza e à terra, tal como fez Mary Wigman (1886-1973).

\footnotetext{
16 Hábitos ligados à dança, à ginástica e inclusive ao hábito de andar de bicicleta (Suquet, 2012, p.58).

7 Outra temática de interesse da pesquisadora, na forma teórica e prática.

18 No século XIX, as danças exóticas aparecem nas grandes cidades europeias através de dançarinas portando trajes orientais como véus, músicas orientais e ainda absorvendo gestos típicos de danças árabes, turcas, persas, hindus, etc. Associadas ao erotismo através do corpo nu. Staszak (2008) considera que a inspiração oriental é parte também da literatura da personagem Salomé e seus sete véus de Oscar Wilde (Salomé). A partir dos anos 1950, o termo também designa danças de caráter erótico como o pole dance.
} 
Anita Berber (1899-1928), artista famosa de cabaret, ela foi uma dessas figuras de dançarinas exóticas depreciadas nesse contexto (Boulbés, 2014, p.39). A prática artística de mulheres como Anita Berber não foi compreendida enquanto ato de libertação do corpo da mulher e de desafio ao poder vigente. Esse panorama permaneceu dessa forma por um longo tempo e se pode dizer que ainda não foi superado. Por esse fato, é que outras artistas de renome, tais como Mary Wigman, Loie Fuller, Ruth Saint-Dennis e Martha Graham (1894-1991) esforçaram-se para se distanciar dessas formas de manifestação relacionadas ao entretenimento, embora alguns tenham se projetado em espaços desse tipo. Em consonância com o pensamento de Dodds (2011), compreendemos o porquê da presença de certos nomes ${ }^{19}$ para se contar a história da dança ocidental, e o porquê da ausência de outros, como nomes de artistas burlescas, ligadas a dança, a exemplo de Josephine Baker (1906-1975), Sally Rand (1904-1979), Bettie Page (1923-2008).

Considerando a era do Jazz, em 1920, existia o interesse por parte das mulheres em explorar seu poder, sexual e econômico, através do corpo. Essa era, por esse e outros motivos, ficou conhecida, no entanto, como uma época de decadência. Na década de cinquenta, houve o boom do cinema e a da revista pornô, além da disseminação de casas topless bar ${ }^{20}$ e peep show ${ }^{21}$. Em meio a essa diversidade de interesses, foi necessário criar, dentre as manifestações que lidavam com erotismo, uma distinção entre a artista teaser e a stripper, distinção que fora importante para o burlesco se afirmar enquanto prática artística. Artistas tais como Theda Bara (1885-1955), Anna May Wong (1905-1961), entre outras, foram imortalizadas pelas imagens cinematográficas desse período.

Para ir à busca dessa legitimidade e distinção, certos contornos foram se definindo, especificando a prática das artistas teasers no burlesco. Dentre as singularidades dessas, significavam os motivos pelos quais a artista performava, o que Dodds (2011) denomina como "reasons to strip" (no caso, motivadas não só por dinheiro, mas atuando por conta de um desejo e escolha artística); e a técnica empregada nos números (tratando-se da necessidade de um aprimoramento técnico que poderia envolver dançar, atuar e cantar). Tratando da técnica, o próprio strip-tease, para as artistas Teaser, se sofisticava, sendo uma técnica codificada e acompanhada de expressões faciais que comentavam as ações do desnudar-se. As artistas poderiam assim, nessa perspicácia, até mesmo zombar do próprio strip-tease através dos gestos e expressões exageradas.

No entanto, ainda que o burlesco se estabelecesse, além de oferecer uma oportunidade ao pensamento vigente com destaque aos valores ligados à mulher, por outro ele não fora ainda bem compreendido pela cultura dos peritos, da critica da arte, trazida pela modernidade, nem pelo movimento feminista florescente de 1960, que inclusive denunciou a prática do strip-tease como uma androcêntrica ${ }^{22}$ objetificação do corpo feminino (Shteir, 2004), o que ofuscou o burlesco por um tempo e retardou um processo de reconhecimento legítimo no meio artístico e na sociedade.

\footnotetext{
${ }^{19}$ Apesar do sucesso de grandes estrelas do burlesco tais como Lydia Thompson (1838-1908), Josephine Baker (1906-1975), Gypsy Rose Lee (1911-1970), entre outras, tais artistas não fizeram parte da história da arte moderna. Seus nomes não se encontram nos tradicionais livros de historia da dança tais como Bourcier (1978) Sachs (1963).

20 Casas em que as garçonetes trabalham sem a parte superior da roupa, ou nuas.

21 Shows pornográficos que podem incluir sexo explícito. O espectador está como voyeur.

22 Prática ou tendência que favorece aos homens.
} 


\section{Revival e a mudança de paradigma}

Uma vez ofuscado, o burlesco strip-tease reemergiu em 1990 em diferentes contextos. Essa época fora chamada de burlesque revival, neo-burlesque ou new burlesque, com forte projeção em cidades como Londres e Nova lorque, entre outras cidades-chave (São Francisco, Chicago, Denver, Nova Orleans, Los Angeles, Seattle, Tóquio). Portanto, a década de noventa foi de suma importância para a renovação de certos archives e para a mudança de paradigma da cronologia burlesca. Salientaremos agora aspectos desse fenômeno artístico, que tangem questões ligadas ao social, para retratar um panorama de atualização de valores e para encaminhar pistas que tentam responder à questão lançada no início do artigo - como a centenária prática burlesca pode ser analisada sob o prisma de uma manifestação reencenada e reinventada por artistas mulheres.

O new-burlesque esteve e está presente tanto em uma cena que poderia ser dita underground, ou pequena produção, como em casas corporativas de luxo, pertencentes à grande produção. Ainda que ambos os contextos - o da pequena e o da grande produção burlesca - criem mercados de trabalho alternativos se comparados ao mercado tradicional das artes, esses mercados podem ser ainda diferenciados, em decorrência da própria prática.

"Quanto menos a performance perturba, maior o público que ela atrai"23 (Dodds, 2011, p.113). Na frase acima, pode-se pensar a discussão sobre a pequena e a grande produção em contraste. A partir da citação e realizando uma leitura de Dodds (2011), compreendemos que as artistas da pequena produção, dos pequenos cabarés, costumam ter a permissão para serem mais radicais em suas performances. Desse modo, essas artistas podem usufruir melhor da possibilidade de autonomia criativa que a arte burlesca oferece. São performances que podem perturbar politicamente e apresentar um fator crítico explícito ${ }^{24}$. Atentamos para o fato de que essa observação não tem o intuito de desmerecer a grande produção, criando uma relação de oposição entre bom e ruim. No entanto, para verificar que valores estão em jogo no ato de encenar, reencenar, o burlesco hoje, essas são reflexões imprescindíveis. Mantemos especial interesse sobre tal panorama, na medida em que instiga uma reflexão que conecta prática e lugar de prática, lugar de prática, demanda e público, gerando valores distintivos para distintos contextos. Uma perfeita ocasião para se analisar os limites entre oportunidade comercial e demanda de consumo ${ }^{25}$.

Enquanto artista do burlesco lido com esses limites em diferentes números e em diferentes contextos de apresentação. Dentro do meu repertório poderia selecionar dois exemplos práticos para ilustrar.

\footnotetext{
23 "the less the performance disturbs, the wider the audience it attracts" (Tradução nossa).

24 Dodds (2011) oferece como exemplo as performances de Darlinda Just Darlinda. Em seu número George Bush, Darlinda tira de sua vagina uma foto do presidente vigente, George W. Bush.

25 Em minha pesquisa de doutorado, compreendo a ponderação da dimensão econômica e mercadológica dessa forma de arte para avaliar práticas e suas relações de poder, valor e dominação.
} 
O primeiro La Torera ${ }^{26}$ : um número típico burlesco, com strip-tease, dançado, coreografado, com figurino brilhante e impecável. Um número versátil que performo em festivais burlescos, bem como na casa de show ${ }^{27}$ que me apresento, ou até mesmo em um show encomendado para o aniversário de 50 anos de um empresário, uma surpresa da esposa para o marido.

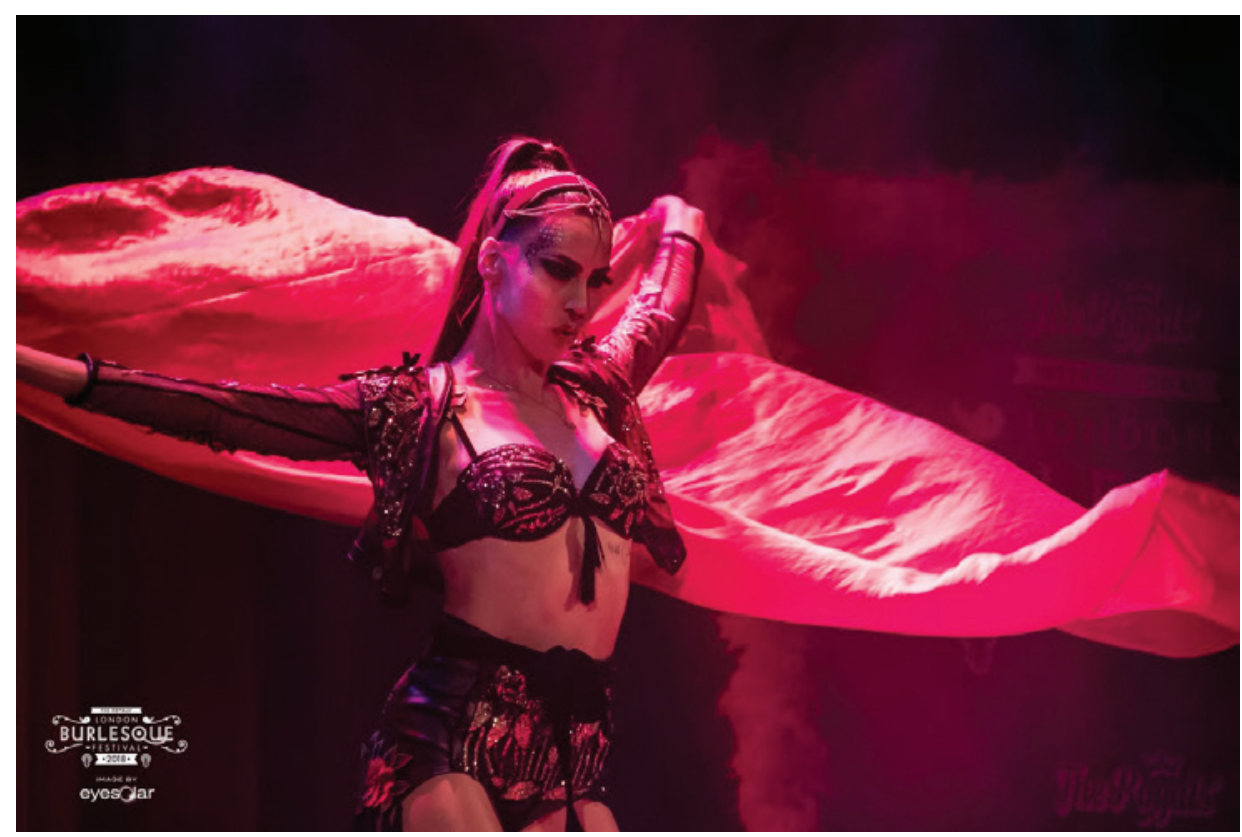

La Torera no LBF - London Burlesque Festival (Londres, RU). Abril de 2018.

Performer: Gabriela Chultz. Foto: Eyesolar.

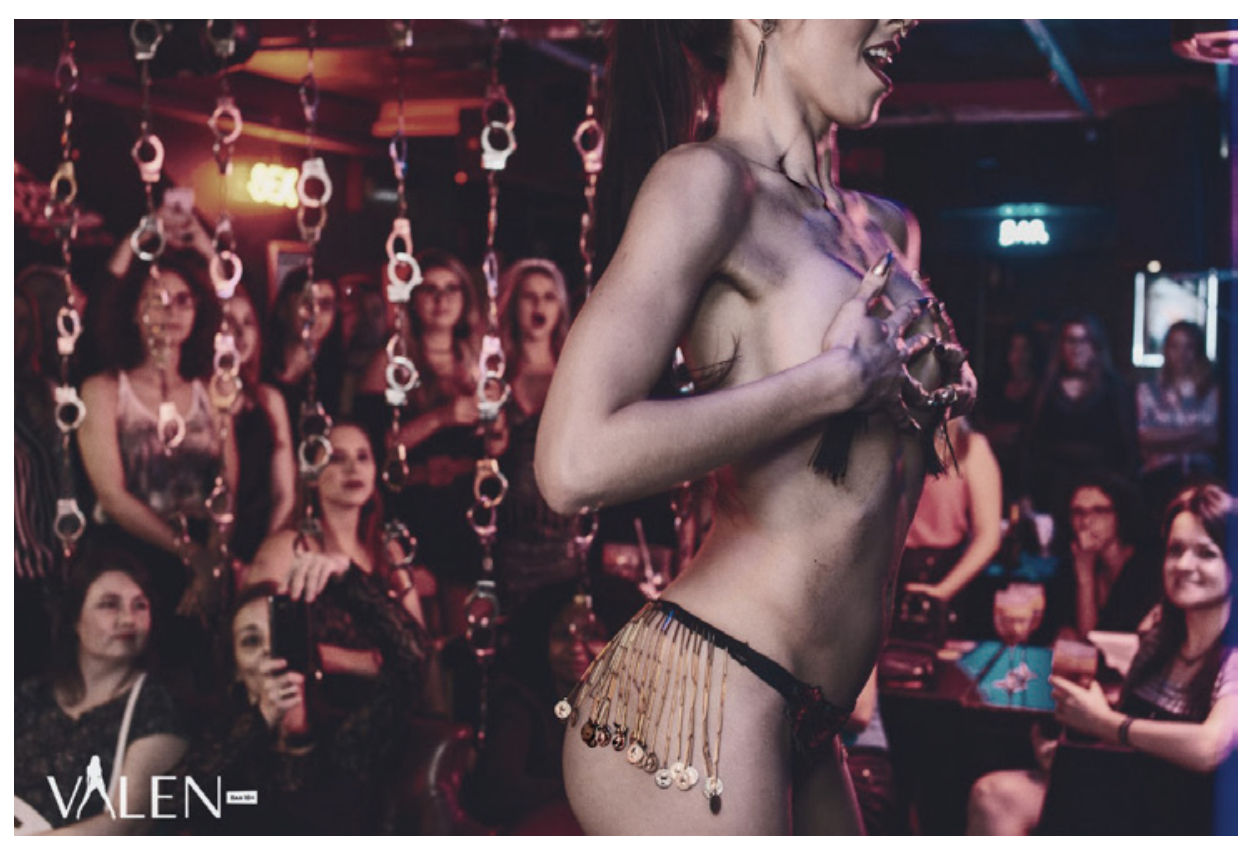

La Torera - na casa Valen Bar (Porto Alegre - RS - BRA). 2017.

Performer: Gabriela Chultz. Foto: Maiquel Borges.

26 Número criado para estrear na casa de show Valen Bar em agosto de 2017, Porto Alegre. A criação conta com o recurso da dança e momentos coreografados, com duração média de 5 minutos. La Torera segue sendo apresentada em Porto Alegre, e também já fora exibida em outras casas de show como 0 Cabert da Cecília (São Paulo - BRA) e nas casas londrinas Proud Cabaret e Cellar Door (Londres - RU), além de estar na programação do LBF - London Burlesque Festival (Londres - RU) no ano de 2018.

27 Primeiro bar temático de erotismo do Brasil (Porto Alegre - RS). Bar para público adulto, com comida, shows artísticos burlescos, e mostra de artes visuais. Mais em: http://valenbar.com.br/ 
O segundo,Sway $\mathrm{Me}^{28}$, trata-se de um número burlesco com dublagem, no qual faço uma brincadeira de gênero. Entro performando um homem, cantando uma música antiga com trajes masculinos tais como calça, gravata, chapéu e bigode. Ao longo do show, junto à mudança da música para uma versão pop, há uma mudança de gênero. Assim, interpretando uma mulher, o gênero feminino é performado através do strip-tease com gestos bastante provocativos e cômicos, utilizando quase um pastiche da ideia de figura feminina. Há dias que esse número não é tão bem compreendido por parte do grande público da casa que me apresento todas as semanas. Embora a casa tenha uma noite burlesca, ainda ensina ao público sobre o que é burlesco a cada apresentação, entendendo sempre que há diferentes expectativas do público. Eu, por exemplo, jamais levaria esse número para apresentar na festa de 50 anos de um empresário, com a intenção de manter boas e estratégicas relações para futuras contrações com a esposa do aniversariante, aumentando a demanda de consumo.

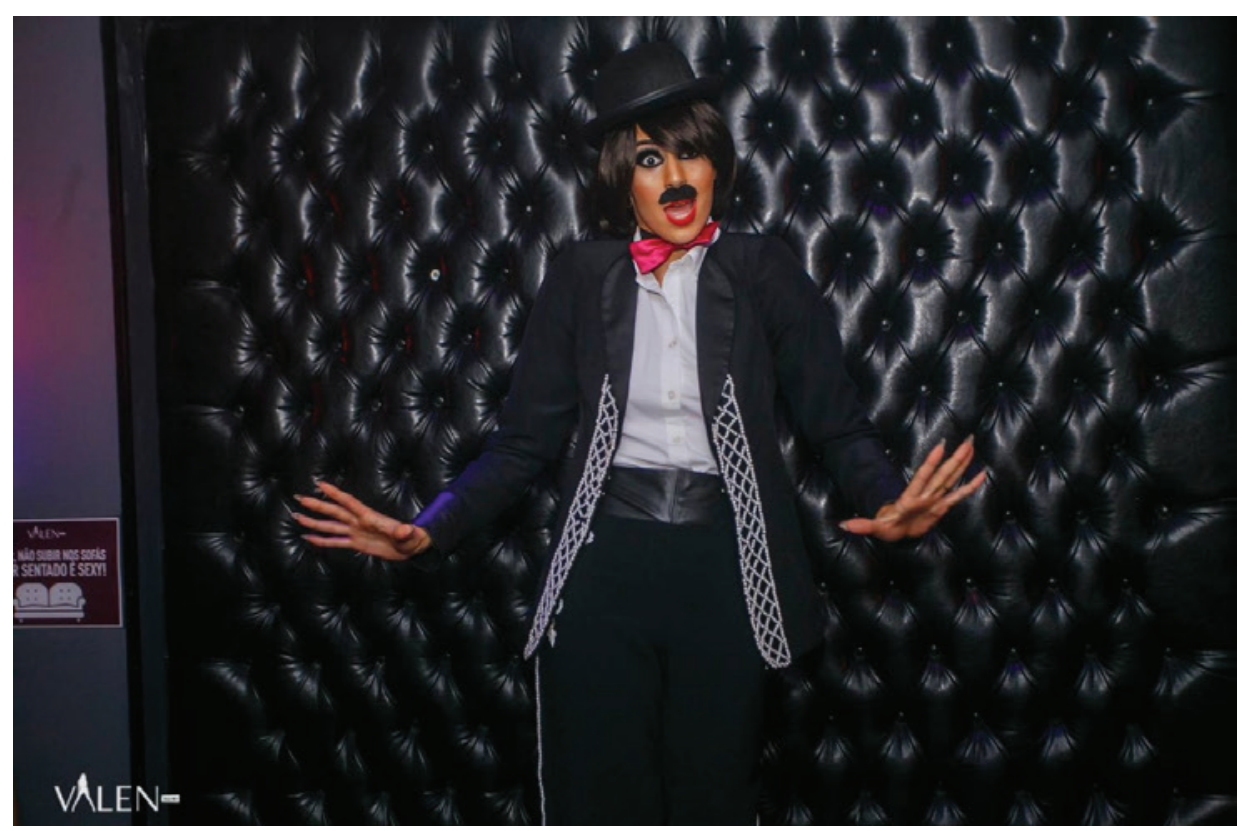

Sway Me - casa Valen Bar (Porto Alegre - RS - BRA). Momento 1 da performance. 2018. Performer: Gabriela Chultz. Foto: Felipe Gaieski.

${ }^{28}$ Número criado em 2018 para ser apresentado no Valen Bar (Porto Alegre). Duração média de 7 minutos. Também apresentado em São Paulo (BRA) e em Londres (RU) durante 0 ano de 2018. 


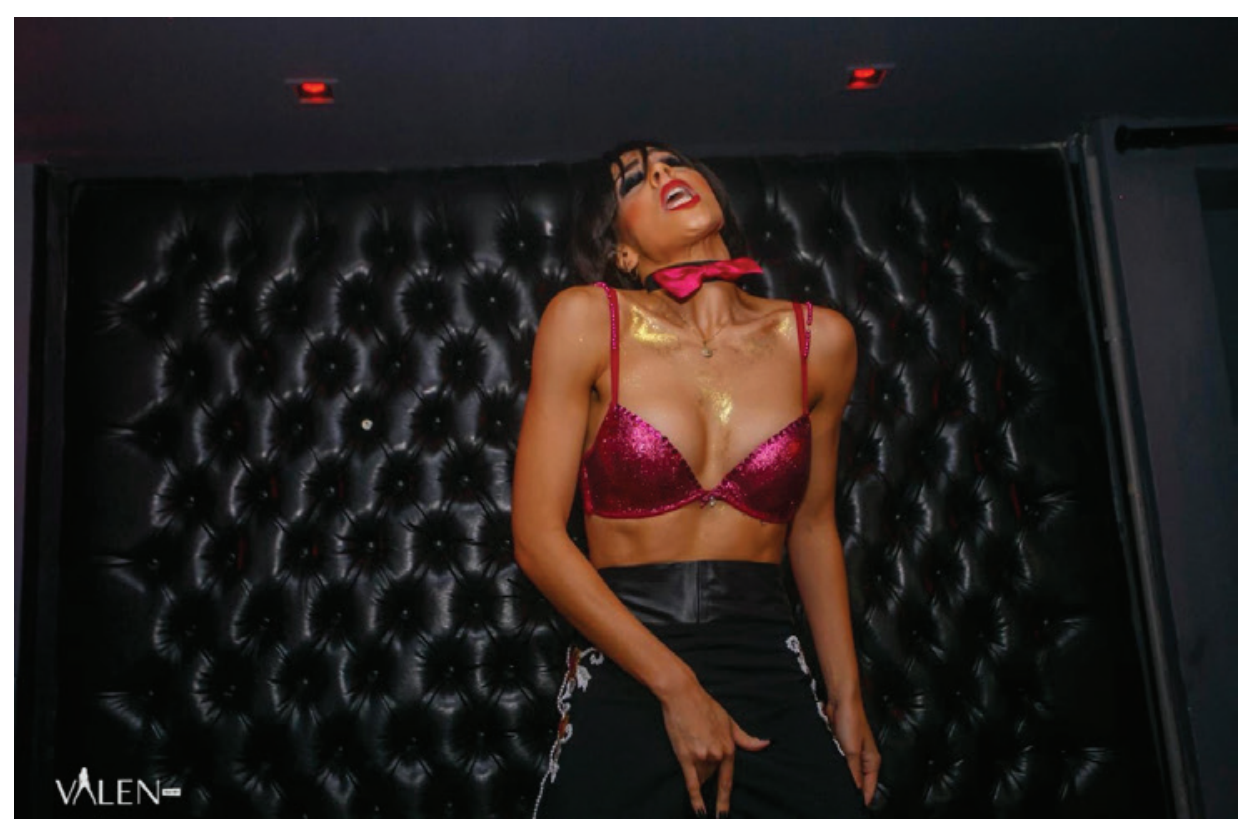

Sway Me - casa Valen Bar (Porto Alegre - RS - BRA). Momento 2 da performance. 2018. Performer: Gabriela Chultz. Foto: Felipe Gaieski.

Esses relatos, de duas experiências de performances, indicam como é possível contextualizar as práticas conforme o tipo de público e o tipo de espaço onde o artista burlesco pode levar seu trabalho artístico. Ainda que existam diferenciações entre os nichos de mercado da cena burlesca, Dodds (2011) aponta a ocorrência, nas produções burlescas como um todo, de importantes mudanças de "regime de valor" (Frow, 1995) que irão penetrar essa prática, e muito diz respeito a uma nova visão de corpo feminino. A primeira mudança discursiva está ligada então a uma reconfiguração da idealização do corpo feminino (Dodds, 2013).

O new-burlesque associou às suas transformações de valores em um maior leque de possibilidades de representação, de tipos de corpos, uma celebração dos diversos corpos, em seus tamanhos, pesos, aparências e idades. Esse leque pode ser mais ou menos versátil e diversificado conforme o nicho de produção. Em grandes casas de shows, essa variabilidade poderá ser menos aparente, mas não quer dizer que ela não exista. Em casas de shows mais alternativas e em festivais burlescos, essa amostra de corpos distintos será ainda maior e será encorajada.

No entanto, como avalia Dodds (2011), em outras questões a diversidade no burlesco é menos aparente, como, por exemplo, se refletidas as questões de classe e de raça. Em seu estudo, a pesquisadora analisou, através de entrevistas, que o burlesco é predominantemente feito por mulheres artistas brancas britânicas ou norte-americanas (com ausência ou minoria de afro-americanas, coreanas e latinas). De forma significativa, conforme as entrevistas, as mulheres tinham um grau de formação escolar e acadêmico elevado, o que sugere um nível alto em capital cultural e social. Das entrevistadas, também poucas tinham o burlesco como atividade profissional "full-time", sendo necessários outros trabalhos para sustentar seus interesses burlescos. Acompanhando a análise da autora, as especificidades, sobretudo culturais, das mulheres entrevistadas conferiam um status simbólico no mundo social, fato que as auxiliam com o discurso do corpo strip-tease, um corpo paradoxal, que pode ser 
visto como sujeito do prazer sexual, símbolo de poder e de autonomia artística, ou ainda julgado enquanto corpo objeto de desejo sexual masculino.

Analisando as relações traçadas entre as novas percepções sobre o corpo feminino no burlesco e a criação de mercados de trabalho por essa arte, entre outras similares, é possível considerar que para além dessa tomada de poder do corpo (artístico, dançante, nu, erótico) existe uma poderosa valorização da própria arte popular, social, e da mulher como referência e protagonista de mercados nesse segmento. É por isso que Dodds (2011) chama a atenção para o fato de as danças populares, onde ela mesma inclui o burlesco, terem a fluida capacidade de se associarem ou angariarem oportunidades comercias no contexto da economia free-market e do empreendedorismo, alimentando um nicho volumoso de profissionais de variadas áreas, relacionadas, por exemplo, a criação de figurino, de maquiagem, a oferta de ensino informal em dança com aulas e cursos em estúdios, aulas online, etc.

$\mathrm{Na}$ contemporaneidade, o new-burlesque carrega seus arquivos e constrói outros, ou reconstrói, renovando sua história e seus valores. A própria prática viva de reenactment, recorrente procedimento da performance art, é bastante empregada nos repertórios de certas artistas do burlesco. Novas interpretações de conhecidos números e de grandes nomes dessa arte, tais como Josephine Baker, Gypsy Rose Lee (1911-1970), Ann Corio (1909-1999), Sally Rand (1904-1979), não são incomuns, o que indica uma reverência a cânones outros, cânones próprios, uma filosofia de criação e manutenção de valores próprios.

Outras partes do mundo, e atentamos agora ao hemisfério sul, vem, passo a passo, sugerindo novos archives para novas cronologias burlescas. No Brasil, cidades como Porto Alegre ${ }^{29}$ e São Paulo ${ }^{30}$, inauguraram nos últimos anos as primeiras casas com shows anunciados enquanto burlescos. Nessas mesmas cidades e ainda outras, como Brasília ${ }^{31}$ e Rio de Janeiro ${ }^{32}$, organizam seus primeiros festivais burlescos. Vale notar então a importância dessas estruturas de mercado, que tornam possível a atuação burlesca e escapam aos tradicionais equipamentos, plataformas e fundos de investimentos culturais. Por ser a única alternativa, tais estruturas se configuram enquanto incentivos privados, de empresários e do movimento de artistas (geralmente mulheres) na construção e promoção dessas atividades.

Talvez tenha sido difícil atentar para o quanto o burlesco desde sua aparição apresenta aspectos de uma arte de vanguarda, evidenciando o que se refere à ousadia da exibição de corpos femininos e liberdade da movimentação na hierarquia das partes dos corpos, o que pode ou não ser mostrado ou movimento, dançado, além da irreverência entre outras atitudes. Muitos desses valores não foram e ainda não são compreendidos, se reduzidos restritamente a aspectos relacionados ao erotismo dos corpos. Tais valores continuam sendo irreverentes por novos e pelos mesmos motivos que assim os tornavam no século passado, fortalecendo agora novas provo-

\footnotetext{
29 Casas com Valen Bar 18 (na qual atuo como artista) e Von Teese High Tea \& Cocktail Bar.

30 Burlesque Paris 6 by Night e Cabaret da Cecília

1 Brasilia Burlesque Festival.

2 Yes, Nós Temos Burlesco.
} 
cações, tais como as questões de gênero, bem como conexões ligadas a capacidade de produzir mudanças sociais em diversos campos que a mulher integra (social, de trabalho, no mundo acadêmico, no mundo artístico).

O burlesco na virada do século XX, se compreendido pela ótica dos dias atuais, no âmbito da historia cultural e de gênero, pode ser circunscrito dentro uma proposta de liberdade de colocar o corpo em cena e romper com os códigos de conduta da época, não só pela nudez e erotização, mas também pela ambiguidade da "performatividade de gênero", de uma "estilização repetida no corpo" (Butler, 2003) - através do travestimento e também de certa atuação do que poderia ser "feminino" e o que seria "masculino".

Se em meados do século XIX os homens faziam papéis femininos, no final desse mesmo século, o burlesco aparece com mulheres performando papéis masculinos de modo paródico. Se pensarmos na condição da mulher nesse período, esse aspecto é algo bastante ousado. Várias foram as artistas desse período que se fotografavam com vestes masculinas, por exemplo. Lembrando que a calça comprida nos ambientes sociais era permitida somente para os homens.

As questões de gênero dentro de uma discussão do burlesco ainda estão em elaboração nesse estudo. No entanto já apontam para o fato de que o burlesco é também uma performance de e sobre gênero. Um dos seus recursos de atuação cênica são as paródias de masculinidades e de feminilidades exacerbadas e em gestos codificados. A complexidade da questão é que somente nas últimas décadas essas noções vêm sendo desconstruídas enquanto categorias universais. No caso da feminilidade, é uma noção que só pode ser entendida a partir de sua oposição binária - o masculino - e isso a partir de um conjunto de características de padrões heteronormativos. Nesse sentido, o burlesco sempre brincou com essas categorias de homem e mulher, ora como estereótipos de desejos, sobretudo no que se refere à mulher; ora jogando com os estereótipos, ambiguidades ou fusão dessas fronteiras, podemos compreender aí parte de seu caráter político e de vanguardismo.

Outra questão que estamos elaborando é de como relacionar o burlesco no Brasil com o teatro de revista brasileiro. Acreditamos que o teatro de revista brasileiro sob a regência de Walter Pinto (1913-1994) é o que temos de mais próximo no hemisfério norte ao que se entende por burlesco. Foi no contexto do teatro de revista que Josephine Baker, por exemplo, veio ao Brasil pela primeira vez, no ano de 1929, na cidade do Rio de Janeiro, e depois retornou algumas vezes, conforme apresenta o livro e história visual Fora do Sério - Um panorama do teatro de Revista no Brasil, de Delson Antunes (2004).

Revisitar momentos da cronologia burlesca, abrir seus arquivos e olhá-los com olhos de pesquisadora, é deparar-se com um fenômeno, que, como dizíamos no início do texto, é social, artístico, cultural e político. Além disso, é um fenômeno do tempo, atrelado a discutíveis regimes de valor (artísticos, econômicos, morais e simbólicos) que nem tanto se modificaram em certas áreas frente à sociedade (valores morais, por exemplo), mas tanto se é possível hoje discutir e interpretar a luz de diversas teorias. A dimensão do corpo dançante na esfera da sensualidade e o protagonismo da mulher frente à sociedade, a mercados de trabalho, entre outras 
esferas, encontra voz e lugar de fala, visibilidade. Compreender, analisar e reinterpretar a cronologia burlesca, seja através da prática ou da reflexão, é, dessa forma, também uma ação de reivindicar espaço dentro de novas cronologias e histórias nos arquivos culturais da arte e da dança.

\section{Referências}

ALLEN, Robert Clyde. Horrible prettiness: Burlesque and American culture. North Carolina: Univ of North Carolina Press, 1991.

ANTUNES, Delson. Fora do sério: um panorama do teatro de revista no Brasil. Rio de Janeiro: FUNARTE, Ministério da Cultura, 2004.

BOULBÈS, Carole et al. Femmes, attitudes performatives. Dijon : Les Presses du réel, 2014.

BOURCIER, Paul. Histoire de la danse en Occident. Paris: Éditions du Seuil, 1978.

BUTLER, Judith. Problemas de gênero: feminismo e subversão da identidade. Trad. Renato Aguiar. Rio de Janeiro: Civilização Brasileira, 2003.

DODDS, Sherrill. Dancing on the Cannon: Embodiment of Value in Popular Dance. Basingstoke UK: Palgrave Macmillan, 2011.

DODDS, Sherril. Embodied transformations in neo-burlesque striptease. Dance Research Journal, Edinburgh UK, v. 45, n. 3, p. 75-90, 2013.

FRANKO, Mark. Epilogue to an Epilogue: Historicizing the Re-in Reenactment. In: VII Congresso da ABRACE, 2015. Arte, corpo e pesquisa na cena: experiência expandida, Belo Horizonte, p. 45-70.

FROW, John. Cultural studies and cultural value. Oxford: Clarendon Press, 1995.

PAVIS, Patrice; GUINSBURG, J. ; PEREIRA, Maria Lúcia. Dicionário de teatro. São Paulo: Perspectiva, 1999.

SACHS, Curt. World history of the dance. Nova lorque: Norton Library, 1963.

SHTEIR, Rachel. Striptease: The untold history of the girlie show. Oxford UK: Oxford University Press, 2004.

STASZAK, Jean-François. Danse exotique, danse érotique. Perspectives géographiques sur la mise en scène du corps de l'Autre (XVIIle-XXle siècles). In: Annales de géographie. Armand Colin, 2008. p. 129-158. 
SUQUET, Annie. L'Éveil des modernités. Une histoire culturelle de la danse (18701945). Pantin : Centre national de la danse, 2012.

TAYLOR, Diana. O arquivo e o repertório: Performance e memória cultural nas Américas. Trad. Eliana Lourenço de Lima Reis. Belo Horizonte: Editora UFMG, 2013.

VENEZIANO, Neyde. O teatro de revista no Brasil: dramaturgia e convenções. Campinas: Pontes, Editora da UNICAMP, 1991.

VENEZIANO, Neyde. Não Adianta Chorar: teatro de revista brasileiro. Oba! Campinas: Editora da UNICAMP, 1996.

VENEZIANO, Neyde. De Pernas para o Ar: teatro de revista em São Paulo. São Paulo: Imprensa Oficial do Estado. Coleção Aplauso. 2005.

VENEZIANO, Neyde. É brasileiro, já passou de americano. Revista Poiésis, Niterói, n. 16, p. 52-61, 2010.

Recebido em: 30/09/2018 Aprovado em: 13/11/2018 